Research Article

\title{
Optimization Research of Artificial Intelligence and Wireless Sensor Networks in Smart Pension
}

\author{
Liqing Li $\mathbb{D}$, Linli Jiang $\mathbb{D}$, and Zixuan Liu $\mathbb{( \mathbb { D }}$ \\ College of Public Management»Law, Hunan Agricultural University, Changsha, China \\ Correspondence should be addressed to Linli Jiang; linlij1997@163.com
}

Received 15 October 2021; Accepted 19 November 2021; Published 30 November 2021

Academic Editor: Punit Gupta

Copyright (C) 2021 Liqing Li et al. This is an open access article distributed under the Creative Commons Attribution License, which permits unrestricted use, distribution, and reproduction in any medium, provided the original work is properly cited.

\begin{abstract}
As a new generation of information technology, artificial intelligence and wireless sensor network are of great significance in promoting the development of "smart pension" and improving the quality of life of the elderly. This paper expounds the application of existing relevant artificial intelligence and wireless sensor network in smart pension, including the daily life of the elderly, health care, and spiritual comfort. This study further puts forward corresponding improvement measures for the existing problems in order to provide ideas for the application of wireless sensor network in smart pension and improve the quality of life of the elderly.
\end{abstract}

\section{Introduction}

Internationally, the population aged 65 and over accounting for $7 \%$ of the total population is generally regarded as the country's entry into an aging society, and China's population structure has moved towards an aging society since the 1990s [1]. Since the 21st century, the problem of population aging in China has become more and more serious. Figure 1 shows the trend of the number and proportion of the elderly population in China from 2013 to 2019. According to the survey data of the National Bureau of Statistics in 2020, the population aged 60 and over in China reached 240.9 million, accounting for $17.3 \%$ of the total population in China; China's population aged 65 and over is 158.31 million, accounting for $11.4 \%$ of China's total population [2]. According to the prediction of China's population development report, in 2050, China's elderly population aged 60 and over will reach $35 \%$ of the total population, while the empty-nest elderly population will account for more than $54 \%$ of the total elderly population [3]. These figures show that the degree of population aging in China is becoming more and more intense, and the trend is very serious.

Under the background of China's aging society, traditional pension is difficult to meet the severe situation. Smart pension has become an important measure to alleviate
China's population aging. Artificial intelligence and wireless sensor network are of great significance in promoting the development speed of "smart pension" and improving the quality of life of the elderly. This paper expounds the application of existing relevant artificial intelligence and wireless sensor network in smart pension, uses artificial intelligence and wireless sensor network to obtain the needs of the elderly at different levels (mainly including the daily life, health care, and spiritual comfort of the elderly), and gives corresponding feedback in time through information processing. It is superior to the traditional pension mode in efficiency and accuracy. This study further puts forward corresponding improvement measures for the existing problems in order to optimize the application of artificial intelligence and wireless sensor network in smart pension, further optimize resource allocation, reduce resource waste, and improve the quality of life of the elderly.

\section{Traditional Pension and Smart Pension}

2.1. Traditional Pension Conceptualization. Maslow's hierarchy of needs theory was proposed by Maslow in 1943, including the five-level model of human needs. From low level to high level, human beings can be divided according to five needs: physiological needs, security needs, social needs, 


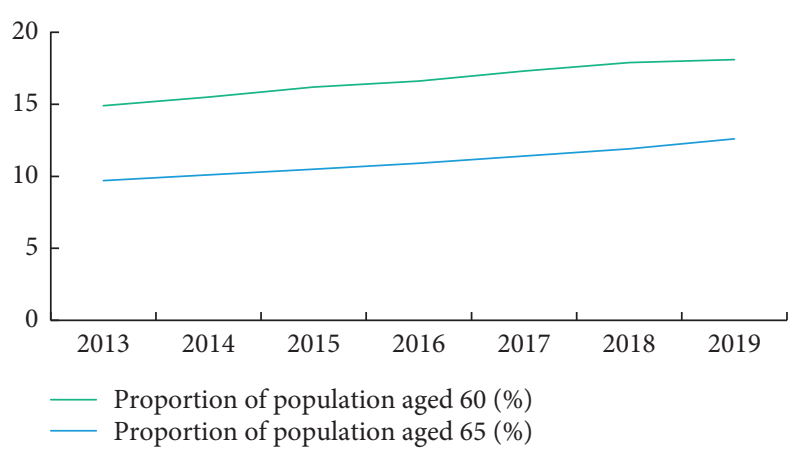

Figure 1: Trend of proportion of elderly population in China from 2013 to 2019 (http://www.stats.gov.cn/).

respect needs, and self-realization needs. Physiological needs and safety needs are the primary-level needs of human beings and the most basic needs of human beings for the safety of themselves and the surrounding environment. Social needs, respect needs, and self-realization needs are human's high-level needs, including human's high-level spiritual needs such as social emotion, social self-esteem, and self-realization. After the primary level needs are met, the high-level needs will become the main needs of individuals.

China's traditional way of providing for the aged has improved the material living conditions of the elderly, which also ensures the primary-level needs of the elderly population. However, the government and society often ignore the senior-level needs of the elderly population at a certain level. For example, due to children's work, family contradictions, age generation gap, and other reasons, children are unable to take care of the elderly 24 hours. Most children give economic subsidies to the elderly at home to meet the needs of the primary level. In addition, a large number of disabled elderly in China can only meet the needs of primary level by means of institutional pension and need 24-hour care workers. According to Huang's survey data, there is an imbalance between supply and demand in China's homebased elderly care and social institutional elderly care, and there is still a gap in meeting the primary-level needs of the elderly population under the traditional elderly care [4].

There is a phenomenon of empty nests in some areas of China. Children tend to send their parents to social pension institutions for care, which leads to the shortage of social pension institutions. In some rural areas, the phenomenon of family empty nest is more serious, but because the elderly care services and elderly care knowledge are not fully popularized, the vast majority of rural elderly can only provide for the elderly at home, which leads to the oversupply of social elderly care institutions. In addition, the current social pension institutions also have problems such as poor service quality and poor structure, such as the inability to meet the daily needs of the elderly, the inability to respond in time to emergencies, the direct inability of society, children, and the elderly to form a channel for timely information sharing and feedback, and the problems of low quality and untimely information transmission in the traditional way of pension [5]. The aging situation of China's social population is very serious, which has brought great unprecedented challenges to China's economic and social security. The traditional way of providing for the aged has been difficult to deal with the problem of aging. It is urgent to develop new ways of providing for the aged.

2.2. Smart Pension Conceptualization. The Fifth Plenary Session of the 19th CPC Central Committee put forward the "implementation of the national strategy to actively respond to population aging," which is closely related to the establishment of the national sustainable development strategy and is related to the harmonious development of people's society. We should deeply understand and implement the directive. Smart pension is a new type of pension service by introducing emerging information technology into the traditional pension mode to connect living homes, communities, and even pension institutions [6]. Using emerging information technologies such as the wireless sensor network to improve the quality of life of the elderly is one of the important measures to alleviate the problem of population aging in China [7]. With the development of artificial intelligence and wireless sensor network technology, its application has also been integrated into the life of the elderly. By improving the quality of elderly care services and the supervision efficiency of elderly care services, it not only improves the quality of life of the elderly but also promotes the continuous development of related technologies. At this stage, the continuous accumulation and development of emerging information technology provides a driving force for various industries. The development speed of artificial intelligence and wireless sensor network technology is accelerating. The traditional pension mode is embedded in emerging information technology. Smart pension is the general trend of pension in the future [8].

\section{Wireless Sensor Network (WSN) Conceptualization}

Based on the development of wireless network, hardware, and sensing equipment, Bill Gates first put forward the concept of wireless sensor network in 1995 [9]. In the subsequent development of the wireless sensor network, it underwent the naming of standardized definition bodies such as IFFF, ITU, 3GPP, and IETF. Ultimately, the wireless sensor network is defined as "a technology by which things or devices can provide users with richer value through their connection to the Internet". In short, the wireless sensor network realizes the information interconnection between things and between people and things through sensors, control chips, action mechanisms, wired or wireless networks, and relevant platform software. Specifically, the wireless sensor network is a network that connects any item with the Internet for information exchange and communication through information sensing equipment such as radio-frequency identification, infrared sensor, Global Positioning System, and laser scanner according to the agreed protocol, so as to realize intelligent identification, positioning, tracking, monitoring, and management. The architecture and key technologies of the wireless sensor 
network mainly include RFID technology, sensor technology, network communication technology, and cloud computing. The basic characteristics of the wireless sensor network can be summarized as comprehensive perception, reliable transmission, and intelligent processing. Through the wireless sensor network technology, objects become intelligent, which can realize the transmission of information with users and provide corresponding services [10] (see Figure 2 for details).

Many Chinese scholars divided China's pension model into family pension, institutional pension, and community pension. At the same time, most scholars believe that the traditional pension service has limitations. The supply methods of artificial intelligence and wireless sensor network in smart pension applications include home life, communities, elderly care institutions, and social organizations. The rapid development of wireless sensor network and other technologies will bring new ideas to traditional elderly care and elderly care services [11]. With the development and application of emerging information technology, artificial intelligence and wireless sensor network will generate a new industrial chain and bring a lot of market value. The informatization level of China's traditional elderly care service system is relatively backward as a whole, but the elderly care service system platform based on artificial intelligence and wireless sensor network technology uses wireless sensor network technology to collect data through terminal equipment and upload relevant information data to the cloud, so as to make the daily life of the elderly in a remote monitoring state. On the one hand, this technology can reduce the cost of elderly care; on the other hand, it can make intelligent elderly care more accurate [12].

\section{AI and WSN in Smart Pension}

4.1. In Daily Life. With the development and shaping of intelligent elderly care, artificial intelligence and wireless sensor network technologies have made the elderly, families, and society enjoy the greatest dividends [13]. China's wireless sensor network technology is used in the daily life of intelligent elderly care, mainly focusing on intelligent home, community service, positioning system, and other services, as shown in Figure 3.

Since the 21st century, in order to enable the elderly to enjoy intelligent services at home, the introduction, development, and application of smart home in China have been maturing. At present, it mainly includes intelligent electrical appliances, lighting control, and other intelligent electrical equipment. The audio and behavior of the elderly are collected through the intelligent terminal device, these data are uploaded to the cloud for analysis and processing by wired or wireless network, and then the feedback information is transmitted to the client. Smart home can also actively monitor and adjust the environmental indicators of the elderly, create an optimal environment for the elderly to live, and reduce the health risk of the elderly.

In the community, artificial intelligence and wireless sensor network technology are used to monitor the information data of the elderly in the community in real time through wearable terminal devices or residential installed terminal devices, upload the data to the network environment for analysis and processing, and provide community door-to-door service or remote service through the feedback information to solve the problems of the elderly in the daily life of the community [14]. For example, installing environmental monitoring devices at home and using wireless sensor network technology to transmit real-time monitoring information with the network environment can ensure the home safety of the elderly on the one hand and provide corresponding feedback through identification information on the other hand. When there is abnormal information such as water leakage, air leakage, and fire at home, the information is uploaded to the network processing system and fed back to the client in real time and the elderly are provided timely assistance through alarm and relevant personnel. At the same time, in case of abnormal data such as water fee, electricity fee, and network fee at home, the information can be fed back to the client for online payment and other convenient services.

The positioning system is mainly to timely and accurately capture the location and behavior information data of the elderly, which is of great help to the elderly group with memory decline and behavioral impairment. At present, the location of the elderly is located in real time through portable intelligent terminal equipment, and the collected location information is uploaded to the network environment. When the environment of the elderly is abnormal and lost, the abnormal data can be analyzed and processed and fed back to the client, and the location of the elderly can be found in time. When an elderly is suspected of falling down, his mobile phone or wearable device or monitoring device can quickly identify whether he has fallen and can automatically complete the call for an ambulance and notify his family.

4.2. Health Care. The empty nest of families and the imbalance between supply and demand of elderly care institutions put the health of the elderly at great risk. The integration of resources in families, medical institutions, and other aspects through artificial intelligence and wireless sensor network technology can reduce the probability of the elderly falling into health risk. China's artificial intelligence and wireless sensor network technologies are used for health care in intelligent elderly care, mainly for real-time selfmonitoring of the body, disease, and living environment. Intelligent terminal devices are used to collect the body, living condition, disease, and other information data of the elderly in real time, then the data are uploaded to the network environment for analysis and processing, and finally the information data are fed back to the client [15] (see Figure 4 for details).

Through the terminal equipment, the health data of the elderly are monitored in real time and uploaded to the network environment for analysis and processing. When the health data of the elderly are abnormal, they are fed back to the client, enabling timely dialing 120 , notifying children in the form of information, and providing community door-todoor rescue and other services. For example, a portable wrist 


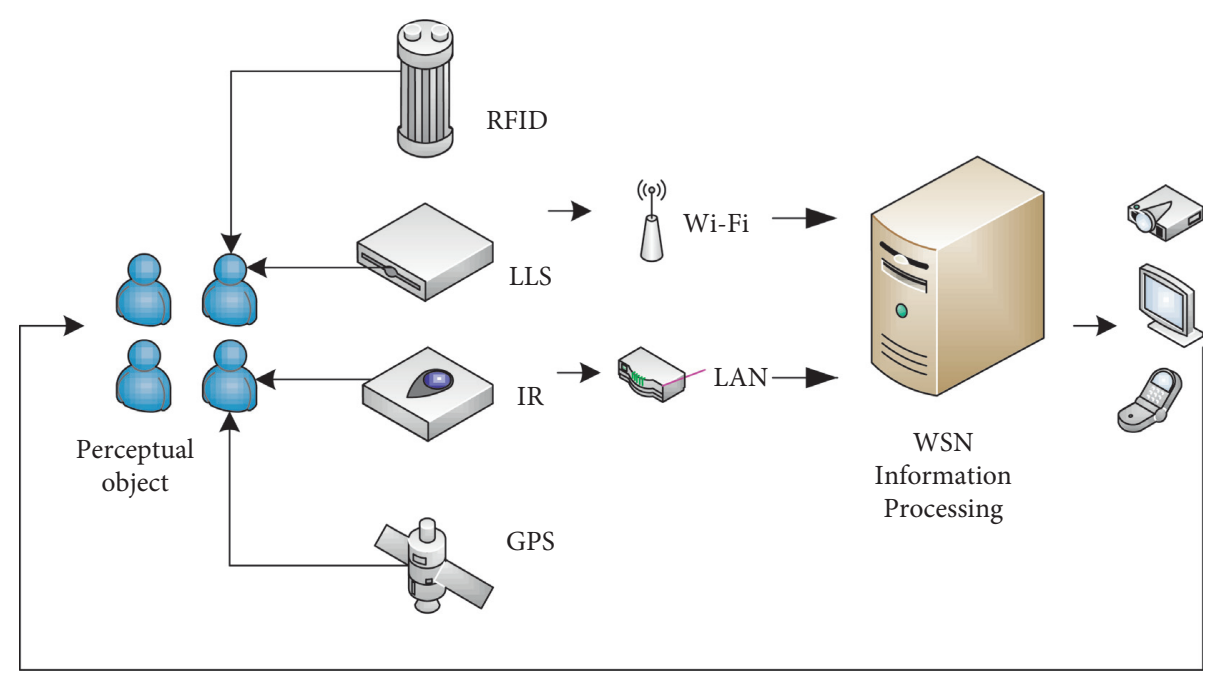

Take actions

FIGURE 2: Basic framework of wireless sensor network system.

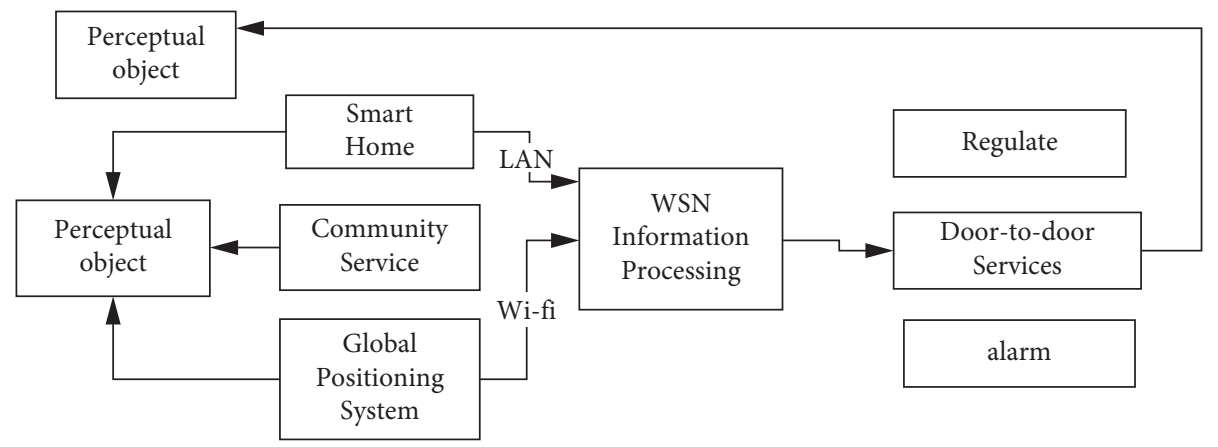

FIgURE 3: AI and WSN in daily life of the elderly.

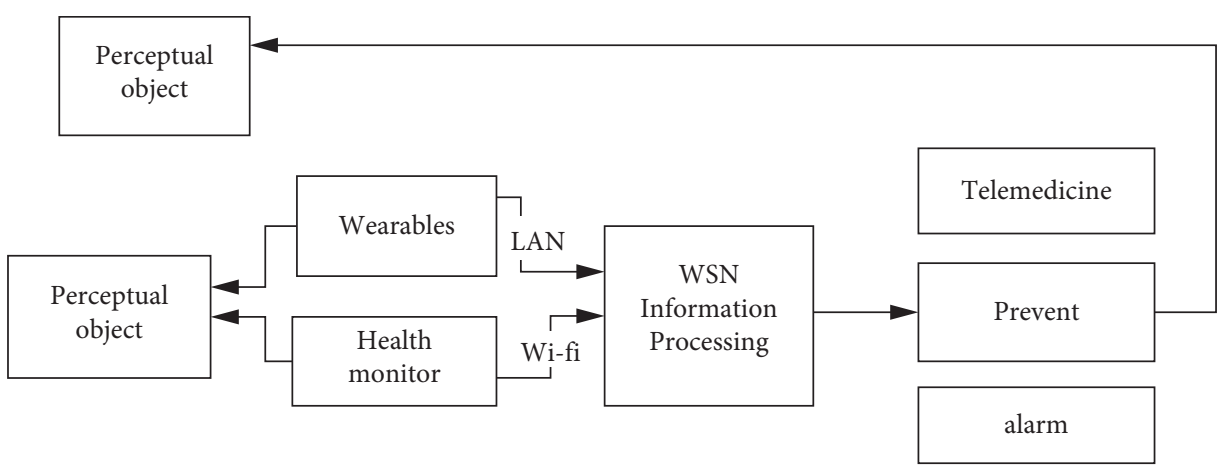

FIgUre 4: AI and WSN in health care of the elderly.

watch has built-in infrared pulse sensor, 3D gravity sensor, and GPS sensor. The collected data are transmitted to the network through wired or wireless network for data processing and analysis, and the feedback results are sent to the client.

In medical institutions, wireless sensors are installed in the living environment of the elderly, the video images and audio of the elderly are monitored in real time and uploaded to the network environment for processing and analysis, and a remote care system is established. Once the collected data are abnormal, they will be warned in time. Especially for the elderly suffering from heart disease, hypertension, and other diseases, they can get the remote escort of medical staff and timely treatment, so as to ensure the health status of the elderly and realize the accurate implementation of medical treatment [16]. 


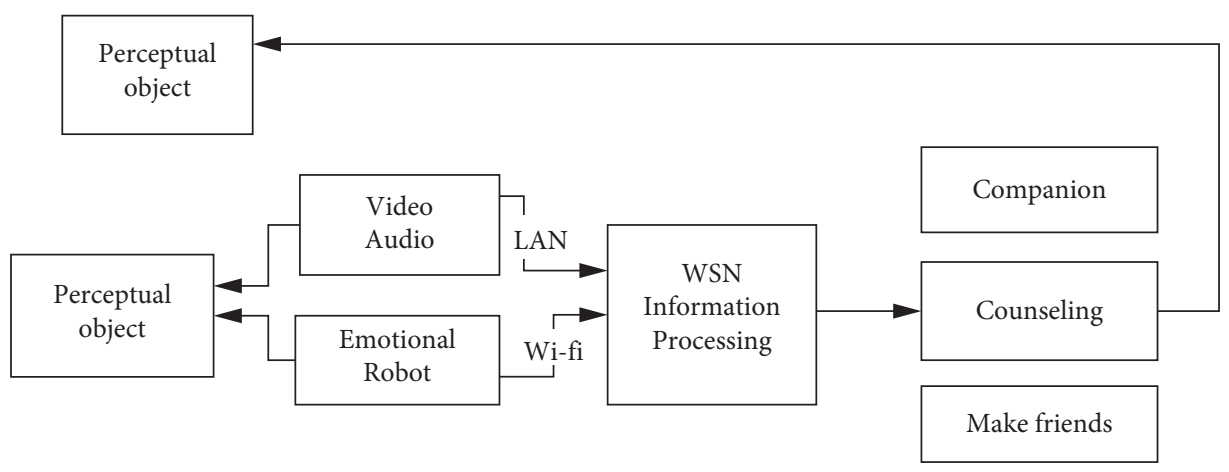

FIgURE 5: AI and WSN in spiritual comfort of the elderly.

4.3. Spiritual Comfort. Empty nests of families have appeared in some areas of China. Due to living habits, intergenerational education, children living in different places, and other reasons, the elderly lack spiritual comfort. China's artificial intelligence and wireless sensor network technologies are used for spiritual comfort in intelligent elderly care, mainly through the elderly and psychological counseling, chatting, promoting hobbies, making friends, contacting children, etc., as shown in Figure 5.

The audio and behavior of the elderly are identified through the intelligent terminal equipment, and the collected information data are uploaded to the processing system for analysis and processing. The processing system should input the emotional algorithm in advance, so as to feed back the corresponding information to the elderly, including chatting with the elderly, psychological consultation, and promoting their hobbies and making friends. The intelligent device has the ability to continuously learn, continuously input the emotional behavior information of the elderly, and learn psychological knowledge, so as to facilitate real-time and accurate spiritual comfort. For example, the smart speaker in our life is an intelligent terminal device, which can send feedback by identifying audio. However, as a special vulnerable group, the elderly need a more targeted identification and feedback system. At present, the spiritual comfort of artificial intelligence and wireless sensor network technology applied to intelligent elderly care is generally based on face recognition and audio recognition. First, face and audio information is collected and uploaded to the processing system with similar thinking mode to human beings, emotional information is analyzed and processed, and finally the emotion needed by the elderly is fed back to the elderly. At the same time, the processing system needs to constantly learn new knowledge, store more useful emotional information of the elderly, and train repeatedly to improve the accuracy [17].

\section{Discussion and Conclusion}

China's living standards and medical standards are gradually improving, and the average life expectancy of the people is also increasing. Under this background, the aging of the population has become a serious social problem. The traditional way of providing for the aged is difficult to meet the severe situation. Intelligent elderly care has become an important measure to alleviate China's population aging. This paper expounds the application of artificial intelligence and wireless sensor network in intelligent elderly care, uses artificial intelligence and wireless sensor network technology to obtain the needs of the elderly at different levels, gives corresponding feedback in time through information processing, which is superior to the traditional elderly care methods in efficiency and accuracy, further optimizes resource allocation, and reduces resource waste. Although the application of artificial intelligence and wireless sensor network technology in intelligent elderly care is conducive to alleviate the tense situation under the background of China's aging population, open up a new market for intelligent elderly care, and improve the quality of life of the elderly population, there are still some deficiencies.

(1) In the daily life of the elderly, intelligent home, community service, and positioning system are the main ways in which artificial intelligence and wireless sensor network technology are applied to intelligent elderly care. Real-time monitoring is carried out through positioning, home feedback, community service feedback, and emergency help. However, the positioning system is easily affected by other signals. As long as it is disturbed by other signals, real-time positioning monitoring will have errors. In the real-time monitoring of the daily life of the elderly, the model used by the positioning system cannot achieve $100 \%$ accuracy, which makes the cloud unable to give the most efficient and accurate feedback when the elderly live at home and encounter individual actions and emergencies. This needs to complement with a variety of positioning models in order to achieve the highest accuracy.

(2) In the health care of the elderly, artificial intelligence and wireless sensor network technology are applied to intelligent elderly care, mainly for real-time selfmonitoring of the body, living conditions, disease and other information data of the elderly in real time, for uploading them to the network environment for analysis and processing, and to feed back the information data to the client. However, health monitoring depends on the performance of the terminal sensor. 
The sensor has some problems, such as time loss, and the elderly cannot maintain it, which will lead to errors in health monitoring. This requires the use of high-performance sensors in the intelligent terminal health monitoring equipment and the provision of regular door-to-door maintenance services, so as to ensure the accuracy of the information and data collected by the intelligent terminal health monitoring, so as to achieve accurate health and medical feedback. At the same time, in terms of health monitoring, the whole process of government supervision shall be implemented to make medical and nursing services transparent and open, so as to protect the rights and interests of the elderly.

(3) In the emotional comfort of the elderly, artificial intelligence and wireless sensor network technologies are mainly through collecting video images and audio from the elderly, and then the recognition system converts them into data that the system can understand. Finally, the emotion recognition system generates corresponding images and voice according to the emotion preference algorithm and outputs them to the elderly. However, due to the unclear emotional expression of the elderly, especially the disabled elderly, there are some difficulties in identifying the emotional behavior and action information of the elderly by artificial intelligence products, and there are also difficulties in analyzing and processing the emotional action information of the elderly in the cloud. This requires regular input of the daily information of the elderly in the processing system of artificial intelligence products. At the same time, combined with the knowledge of psychology to comprehensively analyze the emotional state of the elderly, intelligently communicate with the elderly, so that the elderly has a better grooming effect and chaperoning effect on the spirit. With the further development of technology, the realization will be more and more accurate for the recognition of emotion, language, expression, and other states of the elderly and finally reach the machine and the elderly to communicate without difficulty.

Under the background of the increasingly serious problem of aging in China and the guidance and encouragement of national policies, we should optimize AI and WSN to maximize its effectiveness in smart pension, constantly improve the smart pension service mechanism, and improve the quality of life of the elderly.

\section{Data Availability}

Figure 1 related data belong to public databases National Bureau of Statistics. Users can download relevant data for free for research and publish relevant articles, http://www.stats.gov.cn/tjsj/.

\section{Conflicts of Interest}

The authors declare that they have no conflicts of interest.

\section{Acknowledgments}

This study was supported by the National Social Science Fund Major Project (XSP21ZDA001) and Hunan Postgraduate Research Innovation Funding Project (QL20210160).

\section{References}

[1] M. Zhu and M. Yan, "Population aging and goverrnment expenditure structure: evidence from China based on SD analysis," Journal of Statistics and Information, vol. 34, no. 11, pp. 50-58, 2019.

[2] X. Wang and X. Zhang, "An explanation of China's experience in eliminating absolute poverty and the orientation of relative poverty governance in the post-2020 era," Chinese Rural Economy, vol. 434, no. 2, pp. 2-18, 2020.

[3] China Development Research Foundation, "China development report2020:development trends and policies of China's population aging," 2020.

[4] X. Huang, "A mode research on "artificial intelligence Pension"Service," Journal of Xi'an University of Finance and Economics, vol. 33, no. 5, pp. 35-42, 2020.

[5] D. Sui and X. Liu, "Artificial intelligence home care service modelconstruction," Chongqing Social Sciences, vol. 7, pp. 619, 2020.

[6] H. Zheng, X. Ran, S. Xu, L. Yang, and X. Wang, "Application of artificial intelligence technology in elderly care," Application of IC, vol. 38, no. 9, pp. 184-185, 2021.

[7] J. Zhu, Intelligent Old-Age with the Enablment of Wireless Sensor network, C-Enterprise Management, vol. 411, no. 7, pp. 74-76, 2021.

[8] H. Hu and K. Cai, "Analysis on the development of healthy pension industry driven by artificial intelligence," Chinese Medical Ethics, vol. 33, no. 2, pp. 147152, 2020.

[9] C. Amardeo and J. G. Sarma, "Identities in the future wireless sensor network," Wireless Personal Communications, vol. 32, no. 49, pp. 353-363, 2009.

[10] Z. Xing, "Research on community smart elderly service models and key technologies under the empowerment of artificial intelligence," Chinese Nursing Research, vol. 35, no. 9, pp. 1573-1579, 2021.

[11] Y. Luo, W. Shi, and Y. Xiao, "Change Trends,Existing problems and countermeasures of the modes of endowment for urban residents-_-based on the survey of the modes of the endowment for the aged urban residents in Xi'an," Journal of Xi'an Jiaotong University, vol. 33, no. 1, pp. 78-84, 2013.

[12] S. Miao and P. Peng, "A research of community endowment management system based on wireless sensor network technology," Journal of Guangdong Polytechnic Normal University, vol. 35, no. 3, pp. 15-20, 2014.

[13] K. Tang, "The future development prospect so fartificial intelligence," People's Tribune, vol. 582, no. 2, pp. 24-25, 2018.

[14] A. Alberdi Aramendi, A. Weakley, A. Aztiria Goenaga, M. Schmitter-Edgecombe, and D. J. Cook, "Automatic assessment of functional health decline in older adults based on smart home data," Journal of Biomedical Informatics, vol. 81, pp. 119-130, 2018.

[15] L. Liu, E. Stroulia, I. Nikolaidis, A. Miguel-Cruz, and A. Rios Rincon, "Smart homes and home health monitoring technologies for older adults: a systematic review," 
International Journal of Medical Informatics, vol. 91, pp. 44-59, 2016.

[16] W. W. Jiazy and C. Wang, "Application and development of wearable devices in medical field," China Medical Devices, vol. 32, no. 2, pp. 96-99, 2017.

[17] R. Bellman, An Introduction to Artificial Intelligence: Can Computers Think?, Boyd \& Fraser PubCo, San Francisco, CA, USA, 1978. 